\section{(6) OPEN ACCESS}

\title{
The evaluation and surgical management of cyclodialysis clefts that have failed to respond to conservative management
}

\author{
Alexander S Ioannidis, ${ }^{1,2}$ Catey Bunce, ${ }^{1,2}$ Keith Barton ${ }^{1,2}$
}

${ }^{1}$ NIHR Biomedical Research Centre for Ophthalmology, Moorfields Eye Hospital, London, UK

${ }^{2}$ Department of Epidemiology and Genetics, UCL Institute of Ophthalmology, London, UK

\section{Correspondence to}

Keith Barton,

Moorfields Eye Hospital, 162 City Road, London EC1 V 2PD, UK;

keith@keithbarton.co.uk

Received 27 April 2013

Revised 6 October 2013 Accepted 22 December 2013

Published Online First

23 January 2014

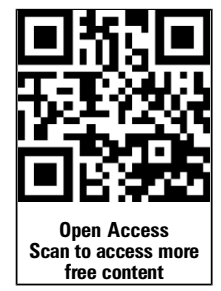

CrossMark

To cite: Ioannidis AS, Bunce C, Barton K. Br J Ophthalmol 2014;98: 544-549.

\begin{abstract}
Purpose To investigate factors that may influence successful correction of hypotony in a consecutive series of patients with cyclodialysis clefts repaired surgically over a 10-year period.

Design Retrospective interventional case series. Methods Interventional case series of consecutive patients with cyclodialysis clefts and hypotony treated surgically after failure of conservative treatment.

Results Eighteen patients (18 eyes) of mean (SD) age 48.3 (15.8) years at the time of surgery were included (16 male, 2 female). All were diagnosed using gonioscopy, usually assisted with intracameral viscoelastic injection. Imaging used in three cases was not found to be sufficiently precise to plan surgical intervention, without prior gonioscopic cleft visualisation. The intraocular pressure (IOP) was restored in nine cases $(50 \%)$ after one procedure with a postoperative IOP (mean $\pm S D)$ of $13.6 \pm 4.5 \mathrm{~mm} \mathrm{Hg}(6 / 11$ who had cyclopexy as a first procedure and 3/6 who had cryopexy). 2-3 procedures were required in the remaining nine patients. There was a trend towards the use of cyclopexy for larger clefts and cryopexy for smaller clefts (NS). We observed a trend for a lower likelihood of successful closure of larger clefts after one intervention. Two eyes that had cyclopexy required later IOP-lowering surgery to achieve IOP control.

Conclusions Most clefts were closed with one procedure. A trend towards larger cleft size as a preoperative risk factor for failure to achieve closure with one procedure was observed. In this series, imaging was not found to be sufficiently precise to replace viscoelastic-assisted gonioscopy in the diagnosis and evaluation of cyclodialysis clefts.
\end{abstract}

\section{INTRODUCTION}

Cyclodialysis clefts occur after blunt trauma or, occasionally after intraocular surgery, when ciliary muscle disinserts from scleral spur, ${ }^{1}{ }^{2}$ permitting aqueous flow from the anterior chamber to suprachoroidal space (figure 1). ${ }^{1}$ They are a relatively rare cause of ocular hypotony and most resolve spontaneously, though some persist with vision loss from hypotony.

A number of repair techniques have been described $^{2}$ but few published series are sufficiently large to compare techniques, ${ }^{3-5}$ and many are of single cases or small series. ${ }^{6-8}$ In addition, the use of imaging has been reported in the diagnoses and localisation of clefts because of the limitations of gonioscopy in a soft eye, ${ }^{5}$ but it is unclear whether imaging is a reliable substitute for gonioscopy.
The purpose of this study is to report outcomes of a series of consecutive patients with clefts requiring surgical management in order to identify factors that might influence surgical success.

\section{METHODS}

Study design and patient eligibility

Retrospective interventional case series of consecutive cyclodialysis clefts repaired either with cryopexy or cyclopexy by one surgeon over a 10 -year period.

Eligible patients were identified from 20 consecutive cyclodialysis clefts that presented to one investigator (KB). Two were excluded: one after spontaneous resolution of the cleft, the other because postoperative follow-up data were not available from the referring ophthalmologist.

\section{Cleft diagnosis}

The cleft was localised using gonioscopy in all cases. If the attachment of iris root/ciliary body to scleral spur could not be identified through $360^{\circ}$ on gonioscopy, gonioscopy was repeated after injection of $0.1-0.2 \mathrm{~mL}$ of Provisc (Alcon, Camberley, UK) at the slit-lamp (figure 2 right, left). Ultrasound biomicroscopy (UBM) and anterior segment optical coherence tomography (AS-OCT) were used in three cases in an attempt to delineate the cleft more accurately.

\section{Surgical methodology \\ Cryopexy}

Viscoelastic (Provisc Alcon UK, Camberley, UK) was injected via a corneal paracentesis and the cleft identified using a Magnaview gonioprism (Ocular instruments Inc, Bellevue, Washington, USA) and coupling fluid (Provisc Alcon UK, Camberley, UK). Using the gonioprism and operating microscope, the cleft was located and cryopexy applied to the cleft area using a $2.5 \mathrm{~mm}$ retinal cryotherapy probe (Ophthalmic Cryo, Mira, Waltham, Massachusetts, USA) to indent and close the cleft while the ice ball formed. A triple freeze-thaw technique was used.

\section{Surgical cryopexy}

Viscoelastic was injected into the anterior chamber via a corneal paracentesis at the start (Provisc). Limbal corneal traction sutures (7-0 silk, Ethilon, Johnson \& Johnson International, Brussels, Belgium) were placed over the area of the suspected cleft.

A limbal conjunctival peritomy was created extending 1 clock hour to each side of the cleft. A circumferential partial thickness scleral flap was 


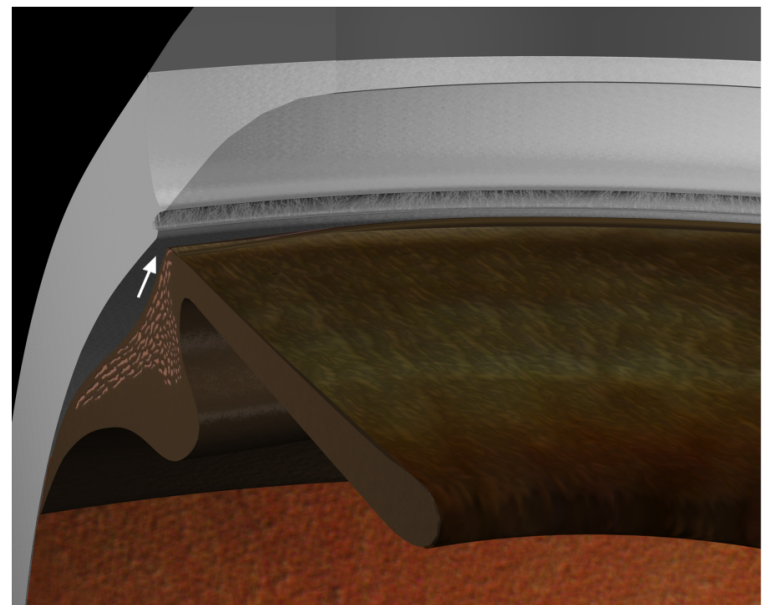

Figure 1 (Courtesy of Alan Lacey.) Diagrammatic representation of the separation of ciliary body from sclera that occurs when a cyclodialysis cleft is formed (white arrow).

outlined, extending 2-3 mm from the limbus and approximately half clock hour to each side of the cleft. The suprachoroidal space was entered at the posterior edge of the flap using a $30^{\circ}$ blade (Microfeather Ophthalmic Scalpel, Medical Division, Feather Safety Razor Company, Japan) (figure 3, top right).

A gush of aqueous at that point confirmed the presence of suprachoroidal fluid but not the cleft location. After opening the scleral flap fully, the suspected cleft area was explored using a cyclodialysis spatula or iris repositor (Duckworth \& Kent Ltd, Hertfordshire, UK) in order to identify the position and limits of the cleft. When the extent of the cleft had been determined, the circumferential width of the scleral flap was extended if necessary.

With the flap fully open, the cleft was visualised directly (figure 3 second row, right and left) and closed by reattaching ciliary body band to the under surface of sclera using two to three 8-0 nylon mattress sutures (Ethilon, Johnson \& Johnson International) (figure 3, third row, right and left). Complete closure was observed by demonstrating absence of flow through the cleft (figure 3, bottom row, left) and confirmed by restoration of the intraocular pressure using Balanced Salt Solution (Aqsia intraocular irrigating solution, Chauvin, Labege, France) injected through the paracentesis. The scleral flap was then closed tightly using 8-0 nylon sutures. In one later case, a stepped flap was made, which was closed using 8-0 nylon in the deeper layer and 10-0 nylon in the more superficial layer, permitting burial of the larger 8-0 nylon sutures underneath the partial thickness flap edge.

Viscoelastic was removed at the end of the procedure by anterior chamber irrigation. Subconjunctival injections of 125 mg cefuroxime (Zinacef; Glaxo Operations UK, Greenford, Middlesex, UK) and $4 \mathrm{mg}$ betamethasone sodium phosphate (Betnesol; Celltech pharmaceuticals limited, Slough, UK) were given at the end of the procedure.

\section{Outcome measures}

In each case, the indication for surgery was persistent ocular hypotony after conservative treatment. The primary outcome measure was restoration of the intraocular pressure (IOP) to a level of $6 \mathrm{~mm} \mathrm{Hg}$ or more. The postoperative gonioscopic appearance of the cleft was also documented (figure 4).

\section{Secondary outcomes}

1. Best corrected Snellen visual acuity (VA) after repair.

2. Loss of IOP control (IOP $>21 \mathrm{~mm} \mathrm{Hg}$ or the requirement for ocular hypotensive medication).

\section{Statistical analysis}

Logistic regression was used to look for any associations between success and age, gender, type of surgery, preoperative IOP, size and location of cleft.

\section{Institutional review board}

This study was approved by the research governance committee at Moorfields Eye Hospital. Research Ethics Committee approval was not required as this study did not involve patient randomisation.

\section{RESULTS}

\section{Patients included}

Eighteen patients (18 eyes) were included (16 male, 2 female) of mean (SD) age 48.3 (15.8) years at the time of surgery. Ocular hypotony failing to respond to conservative management was the indication for surgery in all cases. All procedures were performed between September 1998 and May 2008.

\section{Cleft size, location and cause}

The location of the cleft was variable, and there was no predilection for any particular angle quadrant. Most were small $(\leq 1$ clock hour) (median 1 clock hour; range $0.5-4$ to 5).
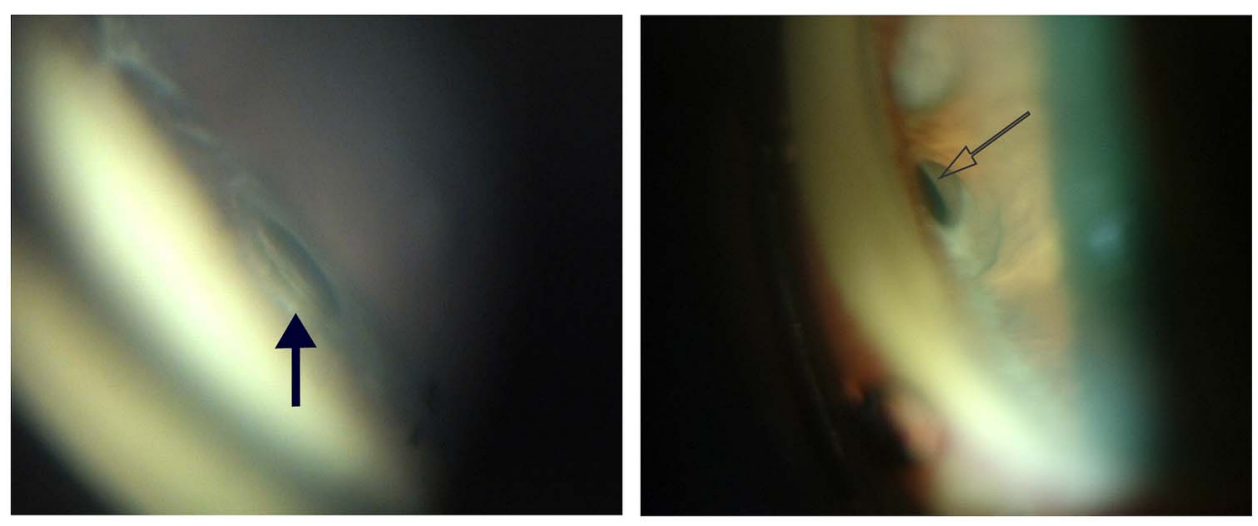

Figure 2 Preoperative appearance of cyclodialysis clefts in two of the reported cases on slit-lamp gonioscopy after intracameral injection of viscoelastic. (Right) Cyclodialysis cleft (solid arrow). (Left) Cyclodialysis cleft partially hidden by peripheral anterior synechiae (open arrow). 

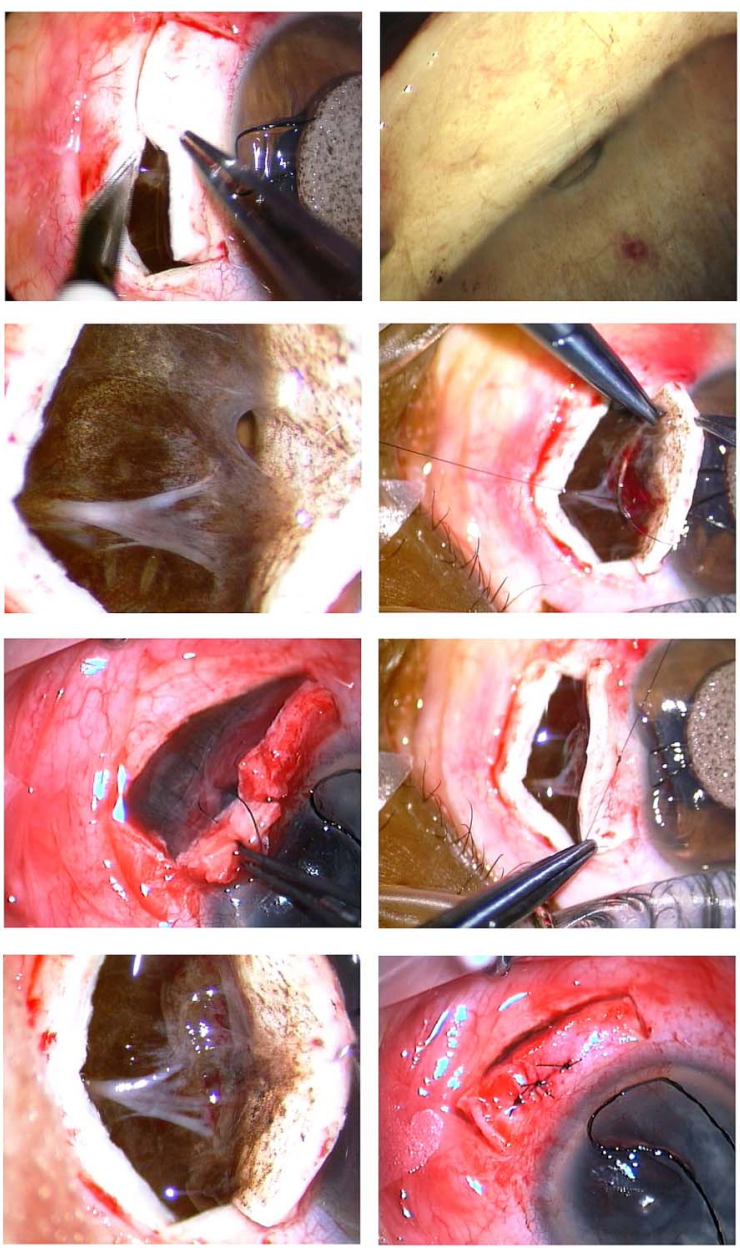

Figure 3 Surgical closure/cyclopexy (top right). Direct visualisation of the cleft (top left). Direct visualisation of long ciliary nerves adjacent to cleft (second row, right and left). Cleft suturing (third row, right and left). External appearance of cleft of scleral flap (fourth row, left).

Fourteen/eighteen clefts resulted from blunt ocular trauma. The remaining four were iatrogenic, two after vitrectomy, one after revision of an aqueous shunt and one created therapeutically in aphakic glaucoma. The median (range) IOP at

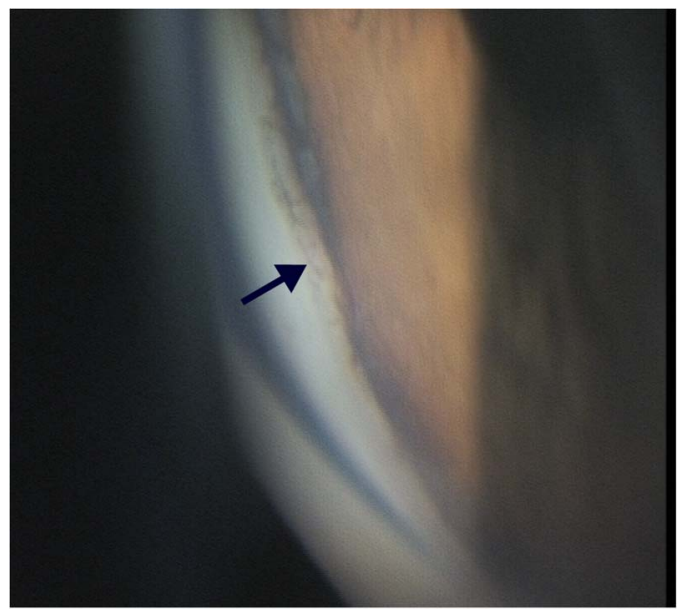

Figure 4 Cyclodialysis appearance on gonioscopy after closure (solid arrow). presentation was $2(0,7) \mathrm{mm} \mathrm{Hg}$. The duration of hypotony prior to repair ranged from 1 month to 7 years (median 17.5 months), excluding four cases in which the duration was unclear from the records.

\section{Closure methods, success rates and follow-up}

In all patients, the IOP was eventually restored to a physiological level. In 9/18 cases, this was achieved with one procedure (IOP at last follow-up: $13.6 \pm 4.5 \mathrm{~mm} \mathrm{Hg}$, mean \pm SD). The duration of follow-up after initial surgery ranged from 4 months to 14.5 years (median 3.9 years).

Cyclopexy and cryopexy as first procedures resulted in cleft closure with no further intervention in $6 / 11$ and 3/6 cases, respectively. The 18th case (a small cleft of 1 clock hour) had failed an attempt at closure using argon laser photocoagulation prior to referral. Subsequently, closure was achieved with cyclopexy with a final IOP of $5 \mathrm{~mm} \mathrm{Hg}$.

Of the $8 / 17$ cases that failed, an initial attempt at closure with either cyclopexy or cryopexy, a second cyclopexy was successfully performed in two cases of large clefts (4-5 clock hours).

In another two cases, multiple procedures were required. In one case, primary cyclopexy was followed by cryopexy and then a second cyclopexy that finally achieved closure. In the second case, the patient developed a high IOP following cyclopexy requiring transscleral diode laser cyclophotocoagulation, trabeculectomy and eventually insertion of an aqueous shunt. The patient whose cyclodialysis cleft had been induced therapeutically for glaucoma required an aqueous shunt to control the IOP after successful cyclopexy.

Of the three cases that failed initial cryopexy, all were successfully closed with subsequent cyclopexy.

Cyclopexy was used as a second procedure after one procedure had failed in six cases (two cyclopexies, one argon laser and three cryopexies) and also in one case as a third procedure after failed cyclopexy and cryopexy). In all six, IOP control was achieved.

\section{Cleft size and success rate}

Logistic regression of successful IOP control after surgical intervention, versus age, gender, type of surgery, preoperative IOP, size of cleft, quadrant and eye, revealed no statistical associations with success, although a trend was observed towards cleft size as a risk factor for failure of cryopexy to successfully close clefts. No other potential risk factors were statistically significant.

\section{VA and IOP results}

Following cleft closure, a postoperative pressure rise over $24 \mathrm{~mm} \mathrm{Hg}$ occurred in $67 \%$ (range $25-58 \mathrm{~mm} \mathrm{Hg}$ ). The mean (SD) peak IOP in these cases was 40.9 (10.13) $\mathrm{mm} \mathrm{Hg}$ and most occurred within a few days of surgery. These events were selflimiting and managed with topical medication with or without additional systemic acetazolamide, except for one case that required glaucoma surgery. Six eyes had a return of best corrected VA to 20/30 or better, in six cases VA was related in some way to the original trauma without clear evidence of persistent vision loss as a result of the prior hypotony. Three cases had persistent choroidal or retinal folds, in one of whom it was not clear whether the reduced vision resulted from the original trauma or from the hypotony. There were also three cases of vision loss from previous retinal detachment, advanced glaucoma in combination with severe myopic chorioretinal degeneration and uncorrected refractive error (one each).

Of the two cases with persistent choroidal folds in the absence of vision loss otherwise associated with the trauma 
(patients 10 and 16), the respective duration of preoperative hypotony was 1 month and 5 years, respectively.

A slight trend was observed for an increase in the likelihood of an IOP spike with increased duration of hypotony. However, this was not significant.

\section{DISCUSSION}

Cyclodialysis clefts are uncommon and most resolve spontaneously. Those that do not are treatable and hence the importance of accurate diagnosis. The diagnosis and management are challenging in a very soft eye, especially when there are other sequelae of trauma. Occasionally the trauma may have occurred in the past, the cleft only developing after subsequent phacoemulsification. There are many case reports but very few sizeable reported series of cyclodialysis cleft repair, the largest being those of Hwang et $a l^{5}$ (32 eyes of 31 patients) and Kuchle and Naumann ${ }^{9}$ (29 eyes). We have previously reviewed the cleft literature. $^{10}$

In the authors' experience, accurate identification requires gonioscopy, usually assisted by injection of viscoelastic at the slit-lamp. In the absence of viscoelastic, even light pressure from a gonioprism is sufficient to close the angle preventing visualisation. The difficulties associated with gonioscopy in a very soft eye were noted by Hwang et al,,$^{5}$ who used UBM to identify and localise clefts prior to surgery. UBM and AS-OCT (figure 5) are often helpful in this respect, especially where a cleft is obscured by PAS (figure 2, left). Hwang et $a l^{5}$ successfully identified all clefts in their series using UBM as the primary diagnostic modality. However, we would not have diagnosed a cleft with certainty based on the illustrated example in that report alone as a continuous channel of communication from anterior chamber to suprachoroidal space is not clearly identifiable. There has been no published formal assessment of the diagnostic precision of UBM to date, and different authors have different criteria for diagnosing a cleft on imaging. We used UBM to localise the cleft in three of our cases (two of these also had AS-OCT) (Visante, Carl-Zeiss, Meditec, Dublin, California, USA) and found this modality less precise in diagnosing and defining the limits of a cleft than gonioscopy unless viscoelastic was also injected into the anterior chamber, thereby negating the advantage of UBM over gonioscopy. In eyes with extensive

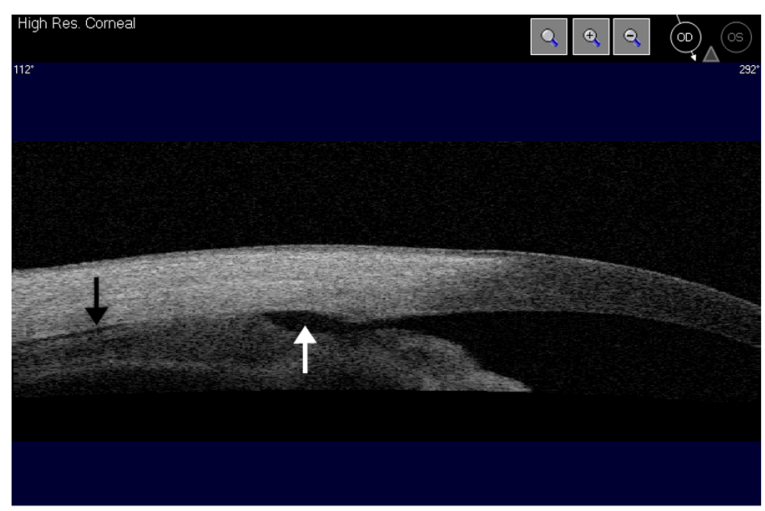

Figure 5 Cyclodialysis cleft visualised on anterior segment optical coherence tomography. Area of separation of ciliary body from sclera is seen (white arrow) along with fluid in the suprachoroidal space (black arrow). Note that a continuous channel is not visible from the anterior chamber to suprachoroidal space in this cut, although the entrance to the cleft can be seen. This illustrates the difficulty in identifying clefts using imaging alone. trauma, multiple clefts may be present. Small clefts either side of a large cleft may be missed without gonioscopic visualisation.

We therefore believe that currently it would be misleading to advise those inexperienced with cleft diagnosis, that imaging techniques are sufficient to exclude the presence of a cleft, unless the anterior chamber has been deepened sufficiently with viscoelastic, not only to stretch open the angle but to prevent it from closing on gonioscopy or UBM.

AS-OCT has the advantage over UBM of higher resolution images without requiring ocular contact and could potentially overcome the need for intraocular injections of viscoelastic, but has the disadvantage of poor penetration of opaque tissues so that the case illustrated in figure 5 is the exception rather than the rule. Despite good visualisation (figure 5) and the positioning of that particular radial cut directly over the cleft, a continuous channel cannot be seen from anterior chamber to suprachoroidal space.

If imaging cannot demonstrate a continuous channel or a significant length of a channel, then a cleft cannot be reliably distinguished from angle recession and cannot be localised with sufficient precision to place a surgical incision. Accurate localisation is especially important for direct cyclopexy as otherwise the scleral flap may either be in the wrong place or insufficient in extent to allow full visualisation (and therefore suturing) of the cleft. On the other hand, the clinical appearance on gonioscopy is distinctive unless obscured by PAS (figure 2).

This study reports experience with patients whose clefts had failed to resolve with conservative management and generally were referred for that reason. Numerous alternative methods of cleft closure have been described. ${ }^{2} 3$ These include argon laser photocoagulation, ${ }^{4} 1112$ which has been reported to be effective in closure of a cleft measuring up to 4 clock hours, though, in the authors' experience, treatment such as laser that is designed to stimulate scarring is unsuccessful unless apposition of the ciliary body band to sclera can be achieved.

Cyclopexy can achieve closure in cases where transscleral cryopexy has failed. In one report, a small cleft at 12 o'clock closed successfully with treatment; however, a similarly sized cleft at 6 o'clock failed to respond requiring cyclopexy. ${ }^{13}$ It may be that the natural tendency for narrowing of the angle superiorly and widening inferiorly aided closure of the former and impeded closure of the latter.

In moderate to large clefts, direct cyclopexy has been shown to be effective in cleft closure. ${ }^{114}$ A number of techniques have been described, including partial scleral flaps (Naumann and Volcker technique), full-thickness scleral flaps (Mackensen and Corydon technique) and the indirect method as described by McCannel. Our approach to surgery has generally been cryopexy for small clefts (around one clock hour) and cyclopexy for larger clefts. The resultant bias makes it difficult to compare the efficacy of the two techniques, except to note that we observed a trend towards more effective closure with cyclopexy. Although the success rates for primary closure were similar, the mean cleft size was smaller in those who had cryopexy (NS).

Our preference for the full-thickness flap is the result of experience with two patients. One developed a very high IOP that resulted in partial dehiscence of the surgical wound (table 1, patient 17) and another who was referred following the same occurrence after cleft closure at another unit (not included as followed up at the referring unit). Partial thickness scleral flaps are more elegant and reduce the risk of protruding 8-0 nylon sutures from eroding through conjunctiva, whereas the full thickness flap permits a more robust closure by permitting larger scleral suture bites, thereby preventing postoperative dehiscence if an extremely high IOP develops. 
Table 1 Patients included

\begin{tabular}{|c|c|c|c|c|c|c|c|c|c|c|c|c|c|c|c|c|}
\hline No. & Sex & Age & $\begin{array}{l}\text { Preoperative } \\
\text { VA (Snellen) }\end{array}$ & $\begin{array}{l}\text { Postoperative } \\
\text { VA (Snellen) }\end{array}$ & Eye & $\begin{array}{l}\text { Associated } \\
\text { pathology }\end{array}$ & $\begin{array}{l}\text { Anterior } \\
\text { segment } \\
\text { imaging }\end{array}$ & $\begin{array}{l}\text { Preoperative } \\
\text { IOP }(\mathrm{mm} \mathrm{Hg})\end{array}$ & $\begin{array}{l}\text { Cleft } \\
\text { location } \\
\text { clock (h) }\end{array}$ & $\begin{array}{l}\text { Clefts } \\
\text { size } \\
\text { clock } \\
\text { (h) }\end{array}$ & $\begin{array}{l}\text { First } \\
\text { treatment }\end{array}$ & $\begin{array}{l}\text { Second } \\
\text { treatment }\end{array}$ & $\begin{array}{l}\text { Third } \\
\text { treatment }\end{array}$ & $\begin{array}{l}\text { Postoperative IOP } \\
\text { after 1st } \\
\text { procedure week } 1\end{array}$ & $\begin{array}{l}\text { Final IOP } \\
(\mathrm{mm} \mathrm{Hg})\end{array}$ & $\begin{array}{l}\text { Reason for } \\
\text { persistent poor } \\
\text { vision }\end{array}$ \\
\hline 1 & $M$ & 66 & $20 / 320$ & $20 / 125$ & L & $\begin{array}{l}\text { Cleft near } \\
\text { tube }\end{array}$ & No & 1 & 12 to 2 & 2 & Cyclopexy & No & No & 16 & 13 & $\begin{array}{l}\text { Previous retinal } \\
\text { detachment and } \\
\text { silicone oil }\end{array}$ \\
\hline 2 & $M$ & 20 & $20 / 60$ & $20 / 40$ & $R$ & $\begin{array}{l}\text { Angle } \\
\text { recession }\end{array}$ & No & 2 & 4 and 6 & 2 & Cyclopexy & No & No & 50 & 13 & $\begin{array}{l}\text { Original trauma } \\
\text { (retinal scarring) }\end{array}$ \\
\hline 3 & $M$ & 26 & HM & $20 / 200$ & L & Iridodialysis & OCT/UBM & 1 & 6 & 1 & Cyclopexy & No & No & 25 & 8 & Original trauma \\
\hline 4 & M & 47 & HM & HM & $\mathrm{R}$ & $\begin{array}{l}\text { Lens } \\
\text { subluxation }\end{array}$ & OCT/UBM & 2 & 9 to 11 & 2 & Cyclopexy & No & No & 46 & 6 & Original trauma \\
\hline 5 & $M$ & 41 & $\mathrm{HM}$ & $20 / 800$ & $\mathrm{R}$ & Iris adhesions & No & 0 & 11 to 12 & 1 & Cyclopexy & No & No & 40 & 17 & Original trauma \\
\hline 6 & M & 37 & $\mathrm{CF}$ & $20 / 60$ & $\mathrm{R}$ & None & No & 2 & 2 to 3 & 1 & Cyclopexy & No & No & 58 & 16 & Original trauma \\
\hline 7 & $M$ & 49 & $20 / 32$ & $20 / 20$ & $\mathrm{R}$ & None & UBM & 4 & 1 to 2 & 1 & Cryopexy & No & No & 7 & 19 & N/A \\
\hline 8 & $\mathrm{~F}$ & 60 & $20 / 60$ & $20 / 32$ & L & None & No & 7 & $\begin{array}{l}12 \text { and } 7 \\
\text { to } 9\end{array}$ & 3 & Cryopexy & No & No & 44 & 12 & N/A \\
\hline 9 & M & 52 & $20 / 60$ & $20 / 60$ & $\mathrm{R}$ & Iridodialysis & No & 4 & 7 & 0.5 & Cryopexy & No & No & 30 & 18 & $\begin{array}{l}\text { Uncorrected refractive } \\
\text { error }\end{array}$ \\
\hline 10 & M & 66 & $20 / 200$ & $20 / 200$ & $\mathrm{R}$ & None & No & 4 & 12 & $4-5$ & Cyclopexy & Cyclopexy & No & 5 & 10 & $\begin{array}{l}\text { Persistent choroidal/ } \\
\text { retinal folds }\end{array}$ \\
\hline 11 & M & 41 & CF & $20 / 60$ & L & $\begin{array}{l}\text { Optic nerve } \\
\text { damage }\end{array}$ & No & 4 & 6 & $4-5$ & Cyclopexy & Cyclopexy & No & 46 & 9 & $\begin{array}{l}\text { Original trauma } \\
\text { (optic nerve damage } \\
\text { and cataract) }\end{array}$ \\
\hline 12 & M & 40 & $20 / 125$ & $20 / 60$ & L & $\begin{array}{l}\text { Subluxated } \\
\text { lens }\end{array}$ & No & 0 & 8 & 1 & Cyclopexy & Tube & No & 37 & 11 & $\begin{array}{l}\text { Original trauma } \\
\text { (subluxated lens) and } \\
\text { persistent choroidal/ } \\
\text { retinal folds }\end{array}$ \\
\hline 13 & M & 77 & $20 / 32$ & $20 / 20$ & $\mathrm{R}$ & Vitrectomy & No & 7 & 6 & 1 & Argon laser & Cyclopexy & No & 18 & 15 & N/A \\
\hline 14 & M & 47 & $20 / 60$ & $20 / 30$ & $\mathrm{R}$ & $\begin{array}{l}\text { Traumatic } \\
\text { cataract }\end{array}$ & No & 4 & 2 & 1 & Cryopexy & Cyclopexy & No & 12 & 9 & N/A \\
\hline 15 & M & 62 & 20/32 & $20 / 32$ & $\mathrm{R}$ & Aphakia & No & 1 & 2 to 4 & 2 & Cryopexy & Cyclopexy & No & 12 & 5 & $\mathrm{~N} / \mathrm{A}$ \\
\hline 16 & M & 31 & $20 / 200$ & $20 / 60$ & $\mathrm{R}$ & None & No & 0 & 3 & 1 & Cryopexy & Cyclopexy & No & 48 & 11 & $\begin{array}{l}\text { Persistent choroidal/ } \\
\text { retinal folds }\end{array}$ \\
\hline 17 & $\mathrm{~F}$ & 70 & $\mathrm{CF}$ & PL & $\mathrm{R}$ & None & No & 0 & 2 & 1 & Cyclopexy & Cyclodiode & Trabeculectomy & 25 & 7 & $\begin{array}{l}\text { Advanced glaucoma } \\
\text { and myopic } \\
\text { chorioretinal } \\
\text { degeneration }\end{array}$ \\
\hline 18 & M & 38 & $20 / 80$ & $20 / 30$ & L & $\begin{array}{l}\text { Angle } \\
\text { recession }\end{array}$ & No & 7 & 9 to 12 & 3 & Cyclopexy & Cryopexy & Cyclopexy & 42 & 11 & $\mathrm{~N} / \mathrm{A}$ \\
\hline
\end{tabular}

$\mathrm{CF}$, counting fingers; HM, hand motions; IOP, intraocular pressure; PL, perception of light; OCT, optical coherence tomography; UBM, ultrasound biomicroscopy; VA, visual acuity. 
Direct surgical closure techniques seem to be effective as either primary or second interventions. Anterior buckling procedures have also been reported to achieve cleft closure based on the principles of retinal detachment surgery. ${ }^{15} 16$

Following cleft closure, reversible postoperative IOP 'spikes' are not uncommon and are well documented in the literature. $^{2}{ }^{9}{ }^{17}$ In this study, the majority developed IOP elevation after successful closure, often in the first week (table 1). Cyclopexy did not appear to cause a higher incidence of IOP spikes. Management with oral and topical ocular hypotensive medication was effective in most cases in controlling the transient IOP elevation. One patient required transscleral diode cyclophotocoagulation, trabeculectomy and eventually insertion of a Molteno tube to control a persistently elevated postoperative IOP. This case had undergone a primary cyclopexy.

No other serious postoperative complications, such endophthalmitis or ciliary body haemorrhage, were observed in this series. Our report supports the existing evidence that surgical cyclopexy with the method described is a successful and safe treatment for large clefts that are unresponsive or too large for cryopexy.

We appreciate the limitations of exploring small numbers using logistic regression, and we do not believe that our failure to identify statistically significant risk factors implies lack of effect. Based on this series, surgical cyclopexy might be a more effective treatment if one procedure has failed, such as cryopexy. Our study does not have the methodology nor the power to perform a direct comparison, though we did observe a trend to a higher success with smaller clefts and cyclopexy.

Contributors $A S I$ and $K B$ were responsible for design of the study. $K B$ was responsible for conduct of the study. ASI was responsible for data collection. KB and $C B$ were responsible for management and analysis. $C B, A S I$ and $K B$ were responsible for interpretation of the data and preparation. $K B$ and $C B$ approved the manuscript.

Funding This work was part funded in the form of partial salary support for KB by the National Institute of Health Research Biomedical Research Centre for Ophthalmology at Moorfields Eye Hospital.

Competing interests None.

Ethics approval Moorfields Research Management Committee.

Provenance and peer review Not commissioned; externally peer reviewed.
Open Access This is an Open Access article distributed in accordance with the Creative Commons Attribution Non Commercial (CC BY-NC 3.0) license, which permits others to distribute, remix, adapt, build upon this work non-commercially, and license their derivative works on different terms, provided the original work is properly cited and the use is non-commercial. See: http://creativecommons.org/ licenses/by-nc/3.0/

\section{REFERENCES}

1 Brubaker RF, Pederson JE. Ciliochoroidal detachment. Surv Ophthalmol 1983;27:281-9.

2 Ormerod LD, Baerveldt G, Green RL. Cyclodialysis clefts: natural history, assessment and management. In: Weinstein GW.ed Open-angle glaucoma. New York: Churchill Livingstone, 1986:201-25.

3 Ormerod LD, Baerveldt G, Sunalp MA, et al. Management of the hypotonous cyclodialysis cleft. Ophthalmology 1991;98:1384-93.

4 Aminlari A, Callahan CE. Medical, laser, and surgical management of inadvertent cyclodialysis cleft with hypotony. Arch Ophthalmol 2004;122:399-404.

5 Hwang JM, Ahn K, Kim C, et al. Ultrasonic biomicroscopic evaluation of cyclodialysis before and after direct cyclopexy. Arch Ophthalmol 2008;126:1222-5.

6 Brooks AMV, Troski M, Gillies WE. Noninvasive closure of a persistent cyclodialysis cleft. Ophthalmology 1996;103:1943-5.

7 Delgado MF, Daniels S, Pascal S, et al. Hypotony maculopathy: improvement of visual acuity after 7 years. Am J Ophthalmol 2001;132:931-3.

8 Caronia RM, Sturm RT, Marmor MA, et al. Treatment of a cyclodialysis cleft by means of ophthalmic laser microendoscope endophotocoagulation. Am J Ophthalmol 1999;128:760-1.

9 Kuchle M, Naumann GO. Direct cyclopexy for traumatic cyclodialysis with persisting hypotony. Ophthalmology 1995;102:322-33.

10 Ioannidis AS, Barton K. Cyclodialysis cleft: causes and repair. Curr Opin Ophthalmol 2010;21:150-4.

11 Joondeph HC. Management of postoperative and post-traumatic cyclodialysis clefts with argon laser photocoagulation. Ophthalmic Surg 1980;11:186-8.

12 Partamian LG. Treatment of a cyclodialysis cleft with argon laser photocoagulation in a patient with a shallow anterior chamber. Am J Ophthalmol 1985;99:5-7.

13 Mushtaq B, Chiang MY, Kumar V, et al. Phacoemulsification, persistent hypotony, and cyclodialysis clefts. J Cataract Refract Surg 2005;31:1428-32.

14 Naumann GO, Volcker HE. Direct cyclopexy in the treatment of the persistent hypotony syndrome due to traumatic cyclodialysis. Klin Monatsbl Augenheilkd 1981:179:266-70.

15 Kutschera E. A simplified procedure in the treatment of the hypotony-syndrome. Klin Monatsbl Augenheilkd 1975;166:834-5.

16 Portney GL, Purcell TW. Surgical repair of cyclodialysis induced hypotony. Ophthalmic Surg 1974;5:30-2.

17 Vannas M, Bjorkenheim B. On hypotony following cyclodialysis and its treatment. Acta Ophthalmol (Copenh) 1952;30:63-4. 